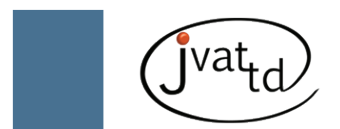

\title{
Histopathological characterization of experimentally induced cutaneous loxoscelism in rabbits inoculated with Loxosceles similis venom
}

Pereira NB (1), Kalapothakis E (2), Vasconcelos AC (1), Chatzaki M (3), Campos LP (1), Vieira FO (1), Verçosa BLA (1), Silva SS (1), Ferreira WM (4), Moro L (1)

(1) Department of General Pathology, Institute of Biological Sciences, Federal University of Minas Gerais (UFMG), Belo Horizonte, Minas Gerais State, Brazil; (2) Department of General Biology, Institute of Biological Sciences, Federal University of Minas Gerais (UFMG), Belo Horizonte, Minas Gerais State, Brazil; (3) Department of Molecular Biology and Genetics, Democritus University of Thrace, Dragana, Alexandroupolis, Greece; (4) Department of Animal Science, School of Veterinary Medicine, Federal University of Minas Gerais (UFMG), Belo Horizonte, Minas Gerais State, Brazil.

\begin{abstract}
Envenomation by Loxosceles bites is characterized by dermonecrotic and/or systemic features that lead to several clinical signs and symptoms called loxoscelism. Dermonecrotic lesions are preceded by thrombosis of the dermal plexus. Recent studies show that atheromatous plaque is prone to thrombosis due to endothelial cell apoptosis. To the best of our knowledge, there are no reports of microscopic dermal lesion and endothelial cell apoptosis induced by Loxosceles similis venom in the literature. Thus, the aim of the present study is to describe histological lesions induced by L. similis venom in rabbit skin and to elucidate whether apoptosis of endothelial cells is involved in the pathogenesis of loxoscelism. Forty male rabbits were split into two groups: the control group (intradermally injected with $50 \mu \mathrm{L}$ of PBS) and the experimental group (intradermally injected with $0.5 \mu \mathrm{g}$ of $L$. similis crude venom diluted in $50 \mu \mathrm{L}$ of PBS). After 2, 4, 6 and 8 hours of injection, skin fragments were collected and processed for paraffin or methacrylate embedding. Sections of $5 \mu \mathrm{m}$ thick were stained by HE, PAS or submitted to TUNEL reaction. Microscopically, severe edema, diffuse heterophilic inflammatory infiltrate, perivascular heterophilic infiltrate, thrombosis, fibrinoid necrosis of arteriolar wall and cutaneous muscle necrosis were observed. Two hours after venom injection, endothelial cells with apoptosis morphology were evidenced in the dermal plexus. Apoptosis was confirmed by TUNEL reaction. It seems that endothelial cell apoptosis and its consequent desquamation is an important factor that induces thrombosis and culminates in dermonecrosis, which is characteristic of cutaneous loxoscelism.
\end{abstract}

Key words: Loxosceles similis, loxoscelism, dermonecrosis, cutaneous loxoscelism, apoptosis.

\section{INTRODUCTION}

Loxoscelism is a set of clinical signs and symptoms that result from the bite of spiders of the genus Loxosceles (1). Clinical manifestations are generally characterized by dermonecrosis at the bite site and sometimes followed by systemic effects, which may cause an acute renal failure and possible death (2-5). Accidents with spiders of the genus Loxosceles have been already described in all continents (2, 4, 6-10). In Brazil, loxoscelism is regarded as a serious public health problem with 51,865 accidents notified from 2001 to 2008 (11). In Minas Gerais, from 2001 to
2008 the number of Loxosceles accidents notably increased. Twenty-one accidents were reported in 2001 but the number rose to 269 and 229 cases in 2007 and 2008, respectively (data not published). From 2005, specimens of L. similis have been found inside residences in Belo Horizonte (Minas Gerais state) increasing the risk of domestic accidents (12).

Reports of $L$. similis lesion are scarce in the literature. Histopathological studies with three Loxosceles species of clinical importance, L. intermedia, L. laeta and L. recluse, showed that the venom induces vasodilation, edema, inflammatory infiltrate (mainly neutrophilic), 
hemorrhage, cutaneous muscle necrosis, thrombosis and arteriolar walls degeneration $(6,13-15)$. It is necessary to elucidate whether the histological lesion induced by the Loxosceles similis venom is similar to that observed in other species of medical importance. Furthermore, it is important to determine the pathogenesis of the loxoscelic dermonecrotic lesion.

A previous study showed that $L$. intermedia venom has a cytotoxic effect on the endothelium and causes a basal membrane lesion (16). This structure is important to maintain the vessels integrity. According to Zanetti et al. (17) and Nowatzki et al. (18) who studied the action of the L. intermedia venom in vitro on endothelial cells, it was observed that 18 hours after the venom action, cells showed plasmatic membrane convolutions and chromatin condensation. These morphological aspects are characteristic of apoptosis, which is an active, energy-dependent kind of cell death that requires protein synthesis and degradation to take place. The necrosis of the cutaneous loxoscelism occurs due to thrombus formation in dermal plexus.

Recent studies have shown a strong relationship between endothelial apoptosis, denudation of the endothelium and the occurrence of thrombosis (19). Therefore, the present work, using an intradermal injection of $0.5 \mu \mathrm{g}$ of $L$. similis crude venom in rabbits as an experimental model, had the following purposes:

- to report a histological lesion caused by the venom;

- to evaluate morphometrically the vasodilation, edema and dermal inflammatory infiltrate 2 , 4, 6 and 8 hours after venom injection;

- to evaluate if the venom induces apoptosis in dermal endothelial cells.

\section{MATERIALS AND METHODS}

\section{Venom}

The venom used was extracted according to previous works and stored at $-80^{\circ} \mathrm{C}(20-22)$. The protein content of the samples was determined by the Bradford method and confirmed by the Lowry method.

\section{Animal Groups and Samples}

Forty male New Zealand rabbits, Oryctolagus cuniculus, weighing between 3.0 and $3.5 \mathrm{~kg}$ were submitted to trichotomy on the interscapular dorsal region. Animals were divided in two groups: the control group $(n=20)$ - received an intradermal injection of $50 \mu \mathrm{L}$ PBS (phosphatebuffered saline); and he experimental group $(n=20)$ - received intradermal injection of 0.5 $\mu \mathrm{g}$ of crude venom diluted in $50 \mu \mathrm{L}$ PBS. Five animals per group were submitted to euthanasia in intervals of 2, 4, 6 and 8 hours after injection.

\section{Histology and Morphometry}

At necropsy, skin fragments were collected and fixed for 48 hours in $10 \%$ buffered formalin $(\mathrm{pH}$ $=7.4$ ). Then, they were sectioned and processed routinely for paraffin inclusion. Sections of $5 \mu \mathrm{m}$ were stained in HE and PAS (23). Skin fragments were also fixed in $4 \%$ paraformaldehyde and processed for methacrylate inclusion using embedding kit (Historesin Leica - specification 7022 31731) according to da Silva (24) and manufacturer's instructions. Semi-thin sections of $3 \mu \mathrm{m}$ thick were stained with toluidine blue and HE (hematoxylin andeosin).

\section{Edema measurement}

Skin thickness was measured in order to quantify the edema. Skin slides were digitalized in stereo microscope, under a $4 \mathrm{x}$ objective and a 3.3 telemetric, which resulted in a final increase of $12 x$. The Pro-plus software calibration was performed by digitalization of a millimeter ruler. Fragment measurement was adapted (25). Skin thickness was calculated by measuring the distance between the epidermis and the muscle layer. Measurements were calculated in three random points of each skin fragment.

\section{Vasodilation measurement}

Vasodilation was quantified by measuring the mean diameter of the blood vessels of HE-stained skin sections from both experimental and control groups. Images were captured using an Olympus BX-640 microscope and digitalized with a JVC TK-1270/JGB camera with an increase of $10 x$. Images were transferred to an image analyzer software (Kontron Electronic, Carl Zeiss KS300, version 2), where the mean diameter of vessels was measured in micrometers. Ten fields were used per animal both for control and for experimental groups, totalizing 50 fields per time interval of 2, 4, 6 and 8 hours $(\mathrm{n}=5$ animals per group). 


\section{Inflammatory infiltrate}

In order to measure the inflammatory infiltrate, the minimal representative number of microscopic fields per sample was determined using one slide from which the number of inflammatory cells per field was analyzed and registered (26). Images were captured from sections stained with HE using a 40x objective. The mean and respective standard errors and coefficients of variation were calculated. Sample size was considered as the minimum representative number of 25 fields (27).

\section{In situ DNA Fragmentation}

In order to identify the in situ DNA fragmentation, TUNEL (terminal deoxynucleotidil transferase uracil nick end labeling) (Calbiochem Kit catalog QIA33) was used according to Gavrieli et al. (28) and the manufacturer's instructions.

\section{Statistical Analysis}

Results were presented as mean \pm standard error, as they presented a normal distribution or not, respectively, according to the KolmogorovSmirnov test. When the distribution was normal, the analysis of variance (ANOVA) and the Newnam Keuls test were applied in order to compare groups. When data distribution was not considered normal, non-parametric KruskalWallis test was applied and Dunn's post-test. Values of $p<0.05$ were considered significant. Statistical analysis was carried out using GraphPad Prism program version 5 .

\section{RESULTS}

\section{Macroscopy}

Macroscopically, the area injected with $0.5 \mu \mathrm{g}$ of Loxosceles similis venom presented a purple, swollen, and touch-sensitive lesion which radius spread out over time (Figure 1).

\section{Histology and Morphometry}

Microscopically, a dissociation of fibers and cells in all dermal layers, which characterizes an edema, was observed in all animals of the experimental group and in all time intervals (Figure 2 - B). Angiectasis (Figure $2-\mathrm{B}$ ), hyperemia, hemorrhage (Figure $2-\mathrm{D}$ ), fibrin exudation (Figure 2 - D), occluding and semi-occluding thrombus (Figure $2-F$ ), on superficial, medium and deep plexus and fibrinoid degeneration of vascular wall were also observed. In all time intervals, the presence of a multi-focal, inflammatory infiltrate was observed (Figure $2-B$ and $\mathrm{C}$ ), particularly in the medium and deep dermis, whose intensity increased over time. The inflammatory infiltrate spread through the muscular layer, followed by muscle necrosis (Figure $2-\mathrm{H}$ ). From 6 hours after the venom injection, the infiltrate became more severe with the formation of perivascular cuffs, which infiltrated into the arteriolar walls characterizing vasculitis (Figure $2-\mathrm{E}$ ).

\section{Edema Measurement}

Means of skin thickness from the control animals were $3.45 \pm 0.12 ; 3.50 \pm 0.20 ; 3.38 \pm 0.17$ and $2.85 \pm 0.10 \mu \mathrm{m}$ for intervals of $2,4,6$ and 8 hours, respectively. Means of skin thickness of animals from the experimental group were: 4.54 $\pm 0.15 \mu \mathrm{m} ; 4.75 \pm 0.21 \mu \mathrm{m} ; 5.08 \pm 0.27 \mu \mathrm{m}$ and $5.10 \pm 0.28 \mu \mathrm{m}$ for intervals of $2,4,6$ and 8 hours, respectively (Figure 3 ). The difference between control and experimental groups was significant in all time intervals.

\section{Vasodilation Measurement}

In order to verify the presence of angiectasis, the mean vessel diameter was measured. Data have shown that mean vessel diameters were $50.97 \pm 5.7 \mu \mathrm{m}, 55.73 \pm 6.4 \mu \mathrm{m}, 57.61 \pm 5.53$ $\mu \mathrm{m}$ and $55.94 \pm 5.45 \mu \mathrm{m}$ for intervals of $2,4,6$ and 8 hours for control groups (Figure 4 ). In the experimental groups, the mean vessel diameters were $91.91 \pm 5.89 \mu \mathrm{m}, 101.7 \pm 8.90 \mu \mathrm{m}, 109.80$ $\pm 10.2 \mu \mathrm{m}$ and $109.90 \pm 9.42 \mu \mathrm{m}$ for intervals of 2, 4, 6 and 8 hours, respectively. The difference between control and experimental groups was significant in all time intervals.

\section{Inflammatory Infiltrate}

Morphometric data of the inflammatory infiltrated from the skin of control animals were as follows: 0.77 cells $\pm 0.14 ; 2.50$ cells $\pm 0.59 ; 1.67$ \pm 0.56 cells and $2.85 \pm 0.89$ cells for intervals of 2, 4, 6 and 8 hours, respectively. The data for experimental animals were: 28.61 cells \pm 1.79 cells; $50.12 \pm 1.63$ cells; $64.75 \pm 1.82$ cells and $105.2 \pm 1.53$ cells for intervals of 2, 4, 6 and 8 hours, respectively (Figure 5). The difference between control and experimental groups was significant in all time intervals. 


\section{In situ DNA Fragmentation}

From two hours of venom injection, the presence of shrunken endothelial cells was observed in some vessels, with loss of cell adhesion (anoikis), retracted nucleus, irregular karyotheca
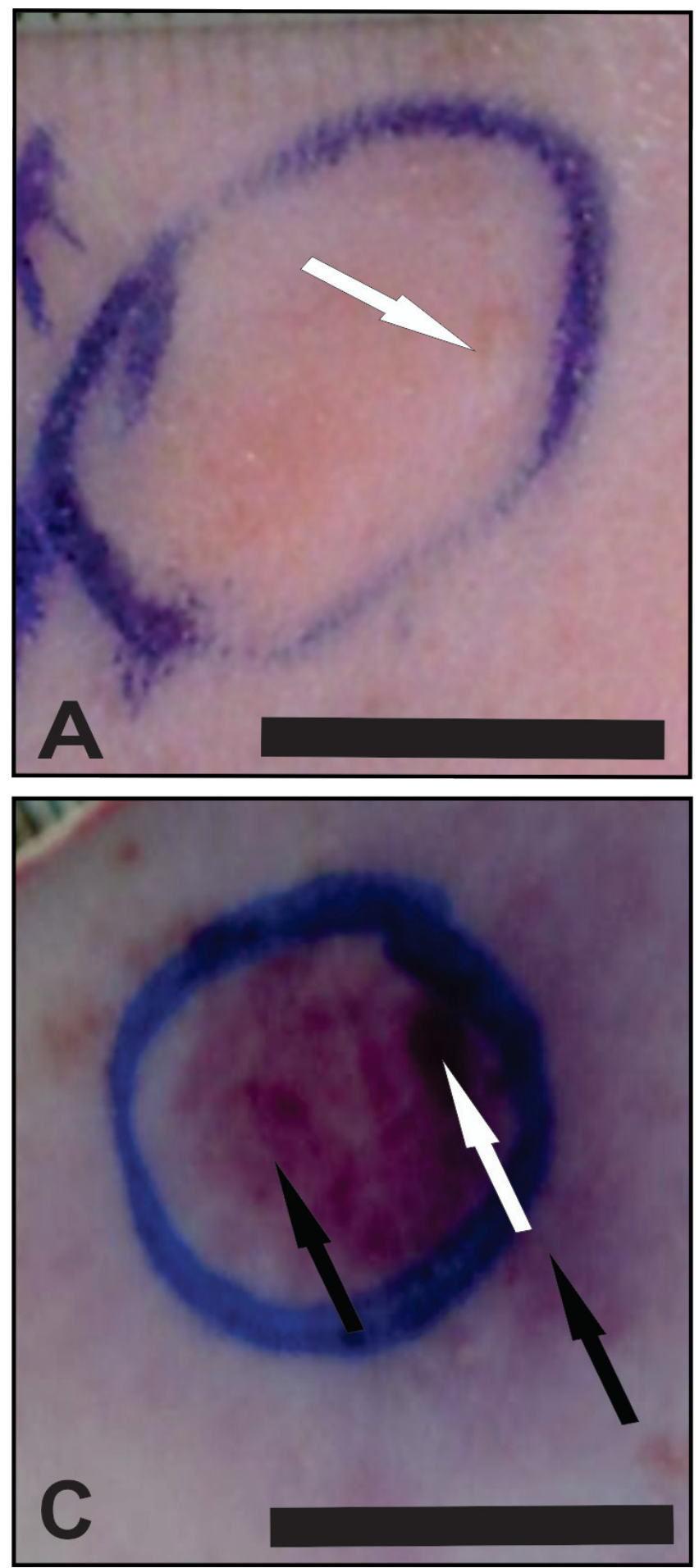

and condensed chromatin (compacted against the karyotheca) characterizing apoptosis (Figure $6-\mathrm{A}$ and B). Furthermore, apoptotic endothelial cells were present in the thrombus-vessel interface from two hours of venom injection. Besides,
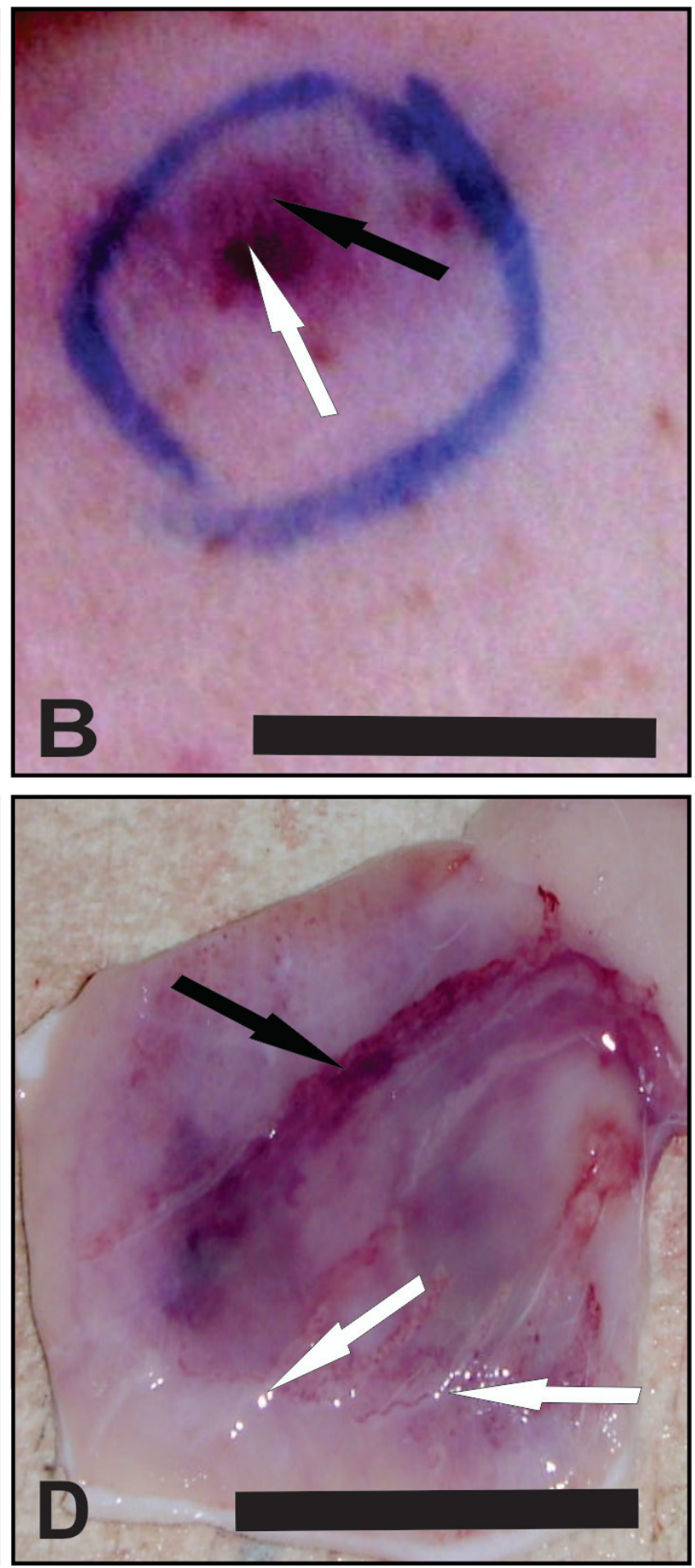

Figure 1. Macroscopic picture of rabbit skin: (A) control group - note the site of injection of $50 \mu \mathrm{L}$ de PBS (white arrow); (B) experimental group - note the site of venom injection (white arrow) and the purple area (black arrow) two hours after injection of $50 \mu \mathrm{L}(0.5 \mu \mathrm{g})$ of crude venom of L. similis; (C) experimental group - 8 hours after the injection of $50 \mu \mathrm{L}(0.5 \mu \mathrm{g})$ of venom, note how the lesion spreads radially (black arrows); (D) experimental group -8 hours after the injection of $0.5 \mu \mathrm{g}$ of venom, note the edema (white arrow) and hemorrhage (black arrow) on the hypodermis. Bar $=1 \mathrm{~cm}$. 

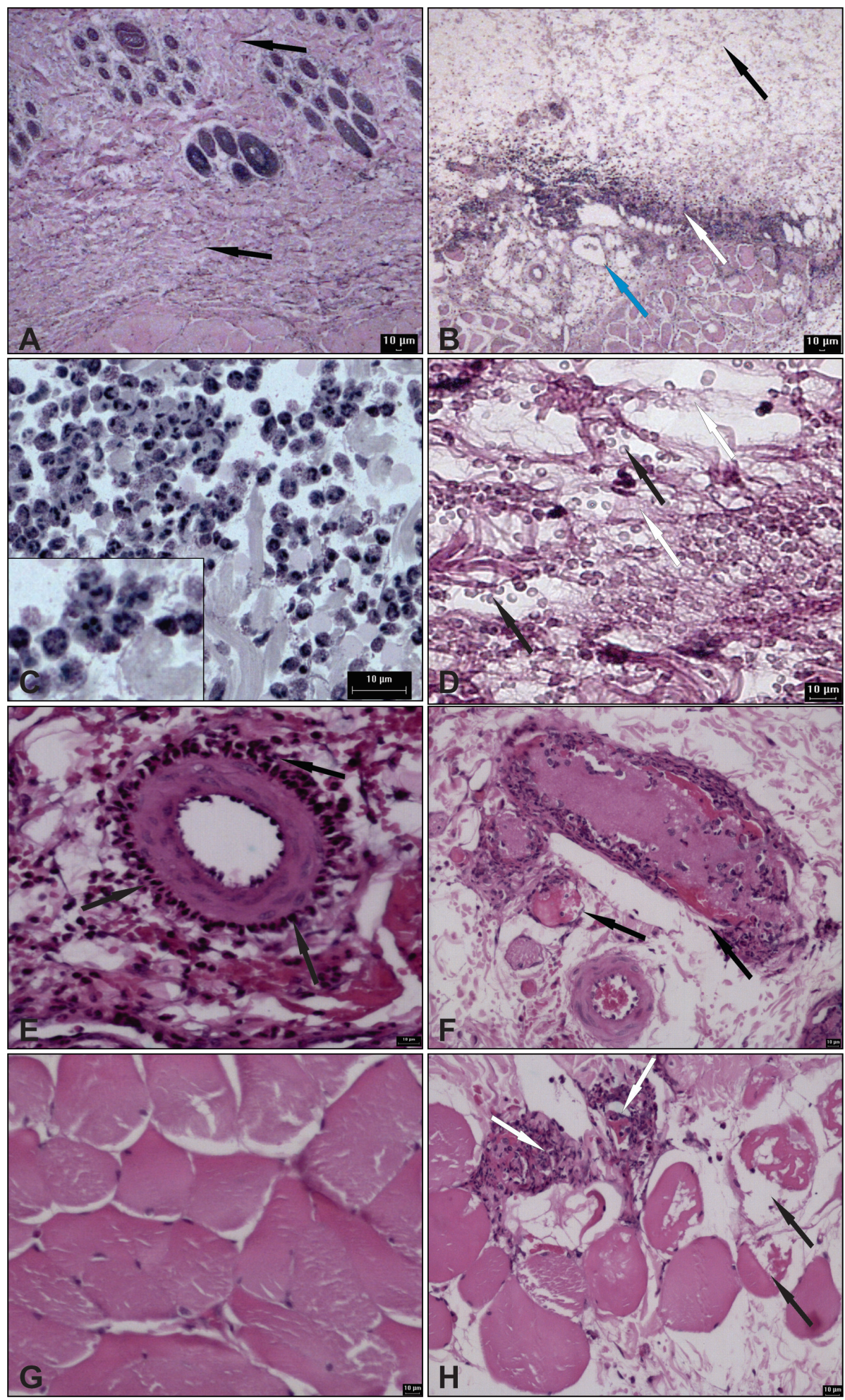

Figure 2. Microscopic picture of rabbit skin: (A) control group - the black arrow indicates the integrity of the collagen fibers; (B) experimental group - note the dissociation of fibers and cells characterizing edema (black arrows), angiectasis (blue arrow), intense inflammatory infiltrate, predominantly heterophilic (white arrow); (C) details of the inflammatory infiltrate (methacrylate, semi-thin section); (D) experimental group - fibrin deposition (white arrows) and hemorrhage (black arrow); (E) perivascular cuff observed 6 hours after venom injection (black arrows), (F) occluding thrombus (black arrows), (G) control group - cutaneous muscle; $(\mathrm{H})$ experimental group - necrosis of the cutaneous muscle (white arrow) and heterophilic infiltration (black arrow). Staining: $A, B, C, E$ and $F=H E ; D=P A S$ counter-stained with hematoxylin. Bar $=$ $10 \mu \mathrm{m}$. 


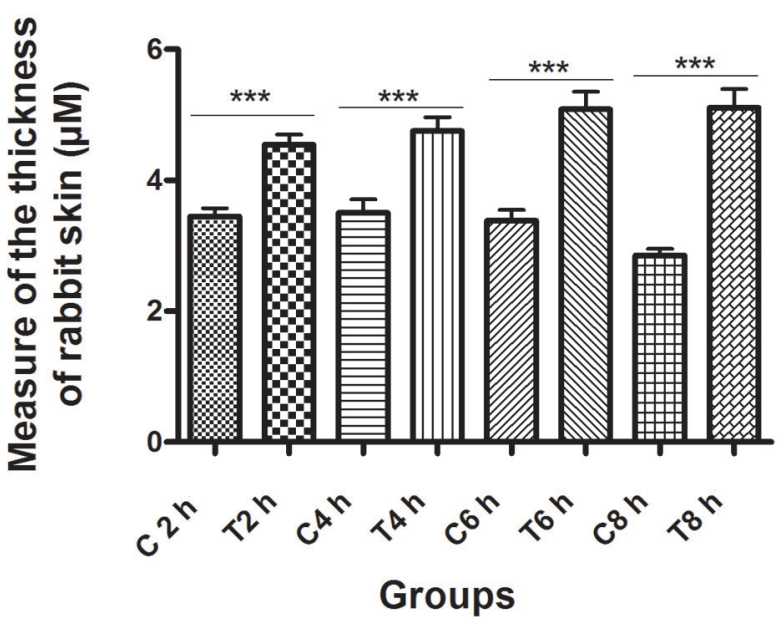

Figure 3. Skin thickness measurement for the edema quantification of the control and experimental groups 2, 4, 6 and 8 hours after injection of PBS or venom. The difference is statistically significant (***p $<0.001 /$ ANOVA and Newman-Keuls tests). $\mathrm{C} 2 \mathrm{~h}, \mathrm{C} 4 \mathrm{~h}, \mathrm{C} 6 \mathrm{~h}$ and $\mathrm{C} 8 \mathrm{~h}=$ control groups $2,4,6$ and 8 hours after PBS injection, respectively. T2h, T4h, T6h and T8h = experimental groups 2, 4, 6 and 8 hours after the venom, respectively.

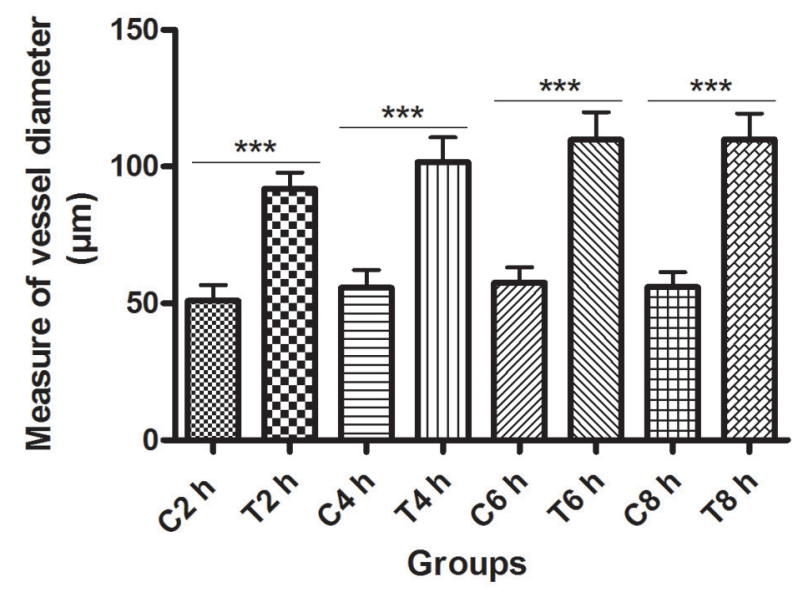

Figure 4. Diameter vessel measurement of control and experimental groups at 2, 4, 6 and 8 hours after $\mathrm{PBS}$ or venom injection. The difference is statistically significant ${ }^{* * *} \mathrm{p}<0.001 /$ Kruscal-Wallis/Dunn's posttest). C2h, C4h, C6h and C8h = control groups 2, 4, 6 and 8 hours after PBS injection, respectively. T2h, T4h, T6h and T8h = experimental groups 2, 4, 6 and 8 hours after venom injection, respectively.

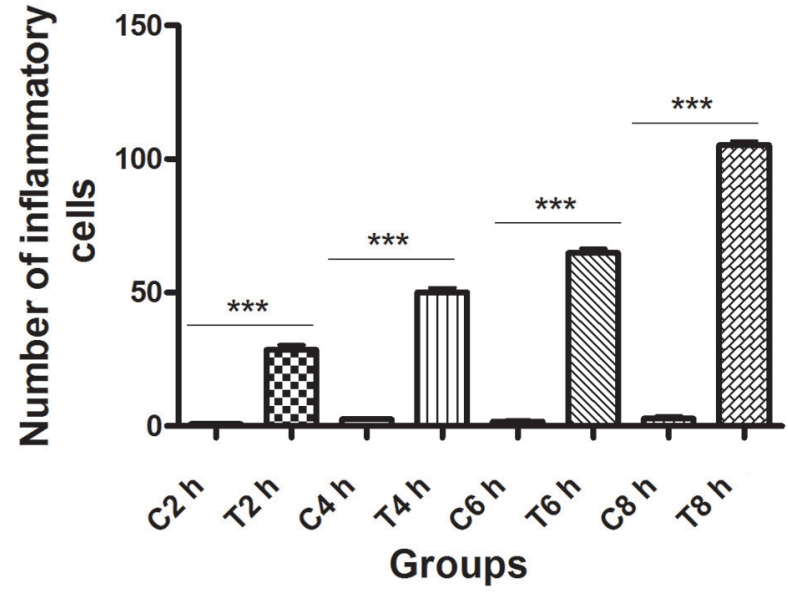

Figure 5. Quantitative analysis of the number of inflammatory cells 2, 4, 6 and 8 hours after PBS (control group) or venom (experimental group) injection. The difference is statistically significant (*** $p<0.001 /$ Kruskal-Wallis/Dunn's post-test). C2h, $\mathrm{C} 4 \mathrm{~h}, \mathrm{C} 6 \mathrm{~h}$ and $\mathrm{C} 8 \mathrm{~h}=$ control groups 2, 4, 6 and 8 hours after PBS injection, respectively. T2h, T4h, T6h and $\mathrm{T} 8 \mathrm{~h}=$ experimental groups 2, 4, 6 and 8 hours after venom injection, respectively.

dermal endothelial cells, positively labeled by TUNEL reaction, were observed and confirmed the morphological evaluation (Figure $6-\mathrm{C}$ and D). The same did not occur in the skin of control animals.

\section{DISCUSSION}

In the present study, the intradermal injection of $0.5 \mu \mathrm{g}$ of Loxosceles similis venom in rabbits induced a warm, swollen, purplish-red and touch-sensitive lesion (acute inflammation), also described by other authors for cutaneous loxoscelism $(6,29)$. Macroscopically, the radius of the injured area increased over time as previously related in loxoscelism induced by other Loxosceles species $(1,6,9)$. Notably, the venom concentration used in this work was very low $(0.5 \mu \mathrm{g})$ compared with our previous study of $3 \mu \mathrm{g}$ of venom, but it was enough to induce a very similar and severe lesion (22). Microscopically, a severe fibrinoushemorrhagic multi-focal acute dermatitis and a necrotic acute myositis were observed. The edema was intense and thrombosis was observed as early as two hours after injection. These lesions 


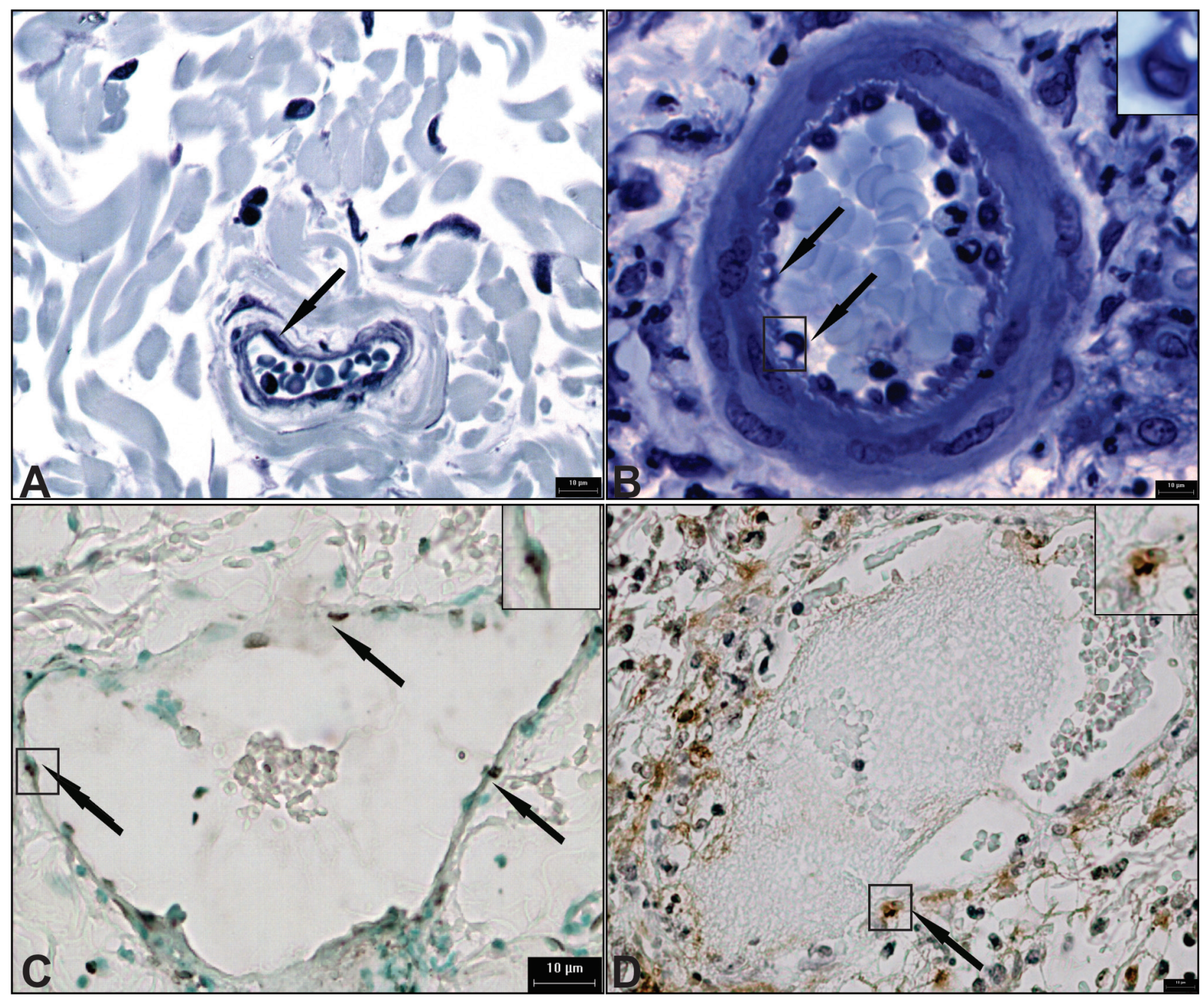

Figure 6. Microscopic picture of rabbit skin: (A) control group - blood vessel - endothelial cell (black arrow); (B) apoptotic endothelial cells (black arrows), (details - insertion on the top right corner); (C) experimental group, two hours after venom injection - presence of apoptotic endothelial cells, labeled positive with TUNEL reaction (black arrow) (details - insertion on the top right corner); (D) experimental group - two hours after venom injection - positive cells for TUNEL reaction in the thrombus-vessel interface (details - insertion on the top right corner). Stainings: toluidine blue ( $A$ and $B$ ) and TUNEL reaction ( $C$ and $D) D A B$ chromogen counter-stained by methyl green. Bar $=10 \mu \mathrm{m}$.

are similar to those observed for other medically important species of Loxosceles (13-15).

In this study, morphometric analyses were carried out in order to follow the progression of the histological lesion through the measurement of edema, vasodilation, and inflammatory infiltrate present in the lesion, considering since there are few reports in the literature regarding these phenomena in loxoscelism. The average diameter of blood vessels was significantly higher $(\mathrm{p}<0.05)$ in experimental animals compared with the control ones, in all time intervals. These data show that $L$. similis venom has a vasodilator action, already observed for other Loxosceles, and which is mediated by histamine $(30,31)$. The edema was significantly greater at 2 hours after venom injection. The present results are similar to those of Rattmann et al. (30) using L. intermedia venom in rat experimental model.

According to our data, the inflammation increases progressively from two hours and then becomes severe eight hours post L. similis crude venom injection corroborating the already existing studies with $L$. laeta and L. intermedia venom $(15,17,32)$. Morphometrical parameters showed here can be used to monitor the process 
dynamics, and also any treatment and sera effectiveness studies $(22,31,33,34)$. In the present study, the heterophils/neutrophils were the predominant cells observed as mentioned by others for loxoscelism. The term heterophil was used instead of neutrophil in the results of this study, as in rabbits and in other species such as guinea pigs, chickens, reptiles and birds; the heterophil is functionally analogous to neutrophils (35-37).

Apoptotic endothelial cells, surrounded by a halo, with shrunken and fragmented nuclei, containing condensed chromatin were observed as early as two hours after the L. similis crude venom injection. The morphology was corroborated by means of a positive labeling of the endothelial cells through the TUNEL reaction. In addition, endothelial cells in apoptosis were present in the thrombus-vessel. Under transmission electron microscopy, Veiga et al. (38) observed the presence of endothelial cell degeneration, characterized by vacuoles on the vessel walls of rabbits skin, four hours after the injection of $30 \mu \mathrm{g}$ of L. intermedia crude venom. Despite of the morphological evidences of apoptosis, the authors did not consider the occurrence of this kind of death cell in that study (38). According to them, loxoscelic venom has a deleterious effect due to destruction of components that are responsible for endothelial cells adhesion. As stated by Bombeli et al. (39), apoptotic endothelial cells become procoagulant due to increased expression of phosphatidylserine and loss of anticoagulant components of the cytoplasmic membrane. Thus, apoptotic endothelial cells contribute to the development of a pro-thrombogenic state (38). Consequently, the presence of apoptotic endothelial cells can contribute to the thrombosis pathogenesis on the cutaneous loxoscelism. According to the Virchow's triad, thrombus formation results from the pathological activation of the blood coagulation process due to rheological blood flow alterations, hypercoagulability and/or endothelial cell lesions.

In the cutaneous loxoscelism, thrombus formation is related to endothelial lesion by the venom direct effect and subendothelial basal membrane alteration (16). Some authors observed that there is a strong relationship among endothelial cell apoptosis, endothelium denudation and thrombosis (19). Besides, they showed that the atheroma plaque desquamation via apoptosis predisposes to thrombosis which is a common consequence of atherosclerosis. So, we suggest that the apoptotic process may also induce loss of cell adhesion and desquamation from the vessel wall, which causes denudation of the vascular surface, exposure of the subendothelial collagen that induces platelet adhesion and aggregation and coagulation cascade activation (40). Once thrombi are formed, dermal necrosis with ulceration takes place and characterizes the loxoscelism cutaneous lesion.

\section{CONCLUSION}

The present data show that the experimental injection of the crude venom of the Loxosceles similis, intradermally in rabbits, induce a histological lesion pattern very similar to that related in the literature for other species of Loxosceles.

Additionally, the results suggest that the induction of endothelial cells apoptosis by the Loxosceles similis crude venom is involved in the pathogenesis of the thrombosis, necrosis and ulceration all characteristics of the cutaneous loxoscelism. Moreover, the dermal inflammation that intensifies over time seems to be an aggravating factor that may contribute to the development of a hard-to-heal ulcer observed in humans.

\section{ACKNOWLEDGMENTS}

We would like to thank the State of Minas Gerais Research Foundation (FAPEMIG) and the National Council for Scientific and Technological Development (CNPq) for supporting the project. We would also like to thank the Coordination for the Improvement of Higher Education Personnel (CAPES) for the scholarship.

\section{COPYRIGHT}

(C) CEVAP 2012

\section{SUBMISSION STATUS}

Received: February 14, 2012.

Accepted: June 14, 2012.

Abstract published online: June 29, 2012.

Full paper published online: August 31, 2012.

\section{CONFLICTS OF INTEREST}

The authors declare no conflicts of interest. 


\section{FINANCIAL SOURCE}

The State of Minas Gerais Research Foundation (FAPEMIG), the National Council for Scientific and Technological Development $(\mathrm{CNPq})$ and the Coordination for the Improvement of Higher Education Personnel (CAPES) provided the financial grants.

\section{ETHICS COMMITTEE APPROVAL}

This study was approved by the Ethics Committee in Animal Experimentation of Federal University of Minas Gerais (CETEA/UFMG 217/2007).

\section{CORRESPONDENCE TO}

Luciana Moro or Núbia Braga Pereira, Av. Antônio Carlos, 6627, Pampulha, Bloco F3-259, Belo Horizonte, MG, CEP 31270-901, Brasil. Email: moro@icb.ufmg.br or nubiologicas@ yahoo.com.br.

\section{REFERENCES}

1. da Silva PH, da Silveira RB, Appel MH, Mangili OC, Gremski W, Veiga SS. Brown spiders and loxoscelism. Toxicon. 2004;44(7):693-709.

2. Sezerino UM, Zannin M, Coelho LK, Gonçalves Júnior J, Grando M, Mattosinho SG, et al. Clinical and epidemiological study of Loxosceles spider envenoming in Santa Catarina, Brazil. Trans R Soc Trop Med Hyg. 1998;92(5):546-8.

3. Málaque CMS, Castro-Valencia JE, Cardoso JL, França FO, Barbaro KC, Fan HW. Clinical and epidemiological features of definitive and presumed loxoscelism in São Paulo, Brazil. Rev Inst Med Trop São Paulo. 2002;44(3):139-43.

4. Hogan CJ, Barbaro KC, Winkel K. Loxoscelism: old obstacles, new directions. Ann Emerg Med. 2004;44(6):608-24.

5. Abdulkader RC, Barbaro KC, Barros EJ, Burdmann EA. Nephrotoxicity of insect and spider in Latin America. Semin Nephrol. 2008;28(4):373-82.

6. Futrell J. Loxoscelism. Am J Med Sci. 1992;304(4):2617.

7. Cohen N, Sarafian DA, Alon I, Gorelik O, Zaidenstein R, Simantow R, et al. Dermonecrotic loxoscelism in the Mediterranean region. J Toxicol Cutan Ocul Toxicol. 1999;18(1):75-83.

8. Nicholson GM, Graudins A. Spiders of medical importance in the Asia-Pacific: atracotoxin, latrotoxin and related spider neurotoxins. Clin Exp Pharmacol Physiol. 2002;29(9):785-94.

9. Swason DL, Vetter RS. Loxoscelism. Clin Dermatol. 2006;24(3):213-21.

10. de Souza AL, Málaque CM, Sztajnbok J, Romano CC, Duarte AJ, Seguro AC. Loxosceles venom-induced cytokine activation, hemolysis, and acute kidney injury. Toxicon. 2008;51(1):151-6.

11. Ministério da Saúde. Brasília: Brasil. Sistema de
Informação de Agravos de Notificação SINAN; [updated 2012 Feb cited 2012 Feb]. Available from: www.saude.gov.br/sinanweb.

12. Machado EO, Álvares ESS, de Maria M, Kalapothakis E. Sobre a presença de três espécies de Loxosceles Heineken \& Lowe (Araneae: Sicariidae) no município de Belo Horizonte, Minas Gerais, Brasil. Lundiana. 2005;6(2):113-5.

13. Smith WC, Micks WD. The role of polimorphonuclear leukocytes in the lesion caused by the venom of the brown spider (Loxosceles reclusa). Lab Invest. 1970;22:90-3.

14. Strain GM, Snider TG, Tedford BL, Cohn GH. Hyperbaric oxygen effects on brown recluse spider (Loxosceles reclusa) envenomation in rabbits. Toxicon. 1991;29(8):989-96.

15. Ospedal KZ, Appel MH, Neto JF, Mangili OC, Sanches Veiga S, Gremski W. Histopathological findings in rabbits after experimental acute exposure to the Loxosceles intermedia (Brown spider) venom. Int J Exp Pathol. 2002;83(6):287-94.

16. Veiga SS, Zanetti VC, Braz A, Mangili OC, Gremski W. Extracellular matrix molecules as targets for brown spider venom toxins. Braz J Med Biol Res. 2001;34(7):843-50.

17. Zanetti VC, da Silveira RB, Dreyfuss JL, Haoach J, Mangili OC, Veiga SS, et al. Morphological and biochemical evidence of blood vessel damage and fibrinogenolysis triggered by brown spider venom. Blood Coagul Fibrinolysis. 2002;13(2):135-48.

18. Nowatzki J, de Sene RV, Paludo KS, Veiga SS, Oliver C, Jamur MC, et al. Brown spider venom toxins interact with cell surface and are endocytosed by rabbit endothelial cells. Toxicon. 2010;56(4):535-43.

19. Xu F, Sun Y, Chen Y. Li R, Liu C, Zangh C, et al. Endothelial cell apoptosis is responsible for the formation of coronary thrombotic atherosclerotic plaques. Tohoku J Exp Med. 2009;218(1):25-33.

20. Silvestre FG, Castro CS, de Moura JF, Giusta MS, de Maria M, Alvares ES, et al. Characterization of the venom from the Brazilian brown spider Loxosceles similis Moenkhaus, 1898 (Araneae, Sicariidae). Toxicon. 2005;46(8):927-36.

21. Pereira NB, Campos PP, de Jesus Oviedo Socarrás T, Pimenta TS, Parreiras PM, Silva SS, et al. Sponge implant in Swiss mice as a model for studying loxoscelism. Toxicon. 2012;59(7-8):672-9.

22. Chatzaki M, Horta CC, Almeida MO, Pereira NB, Mendes TM, Dias-Lopes C, et al. Cutaneous loxoscelism caused by Loxosceles similis venom and neutralization capacity of its specific antivenom. Toxicon. 2012;60(1):21-30.

23. Garvey W, et al. A modified Verhoff elastic van Geison stain. J Histotechnol. 1991;14(2):113-4.

24. da Silva ER. Técnicas rotineiras de preparação de material biológico em microscopia eletrônica de transmissão. Programa de pós-graduação em biologia celular. Instituto de Ciências Biológicas, Universidade Federal de Minas Gerais: Belo Horizonte; 2007. 37p.

25. Chorilli M, Zague V, Ribeiro MCAP, Leonard GR, Pires-de-Campos MSN, Palocow MCO. Avaliação 
histológica da pele após exposição à gel acrescido de hialuronidase associado ou não a ultra-som. Lat Am J Pharm. 2007;26(1):26-30.

26. Moro L, de Sousa Martins A, de Moraes Alves C, de Araújo Santos FG, Carneiro RA, Carvalho R, et al. Apoptosis in canine distemper. Arch Virol. 2003;148(1):153-64.

27. Sampaio IBM. Estatística aplicada à experimentação animal. Belo Horizonte: Fundação de Ensino e Pesquisa em Medicina Veterinária e Zootecnia. 1998. 264p.

28. Gavrieli Y, Sherman Y, Ben-Sasson SA. Identification of programmed cell death in situ via specific labeling of nuclear DNA fragmentation. J Cell Biol. 1992;119(3):493-501.

29. Ribeiro RO, Chaim OM, da Silveira RB, Gremski LH, Sade YB, Paludo KS, et al. Biological and structural comparison of recombinant phospholipase D toxins from Loxosceles intermedia (brown spider) venom. Toxicon. 2007;50(8):1162-74.

30. Rattmann YD, Pereira CR, Cury Y, Gremski W, Marques MC, da Silva-Santos JE. Vascular permeability and vasodilation induced by the Loxosceles intermedia venom in rats: involvement of mast cell degranulation, histamine and 5-HT receptors. Toxicon. 2008;51(3):363-72.

31. Barbaro KC, Lira MS, Araújo CA, Pareja-Santos A, Távora BC, Prezotto-Neto JP, et al. Inflammatory mediators generated at the site of inoculation of Loxosceles gaucho spider venom. Toxicon. 2010;56(6):972-9.

32. Patel KD, Modur V, Zimmermann GA, Prescott SM, McIntyre TM. The necrotic venom of the brown recluse spider induces dysregulated endothelial cell-dependent neutrophil activation. Differencial induction of GM-CSF, IL-8 and E-selectin expression. J Clin Invest. 1994;94(2):631-42.

33. de Moura J, Felicori L, Moreau V, Guimarães G, Dias Lopes C, Mokina L, et al. Protection against the toxic effects of Loxosceles intermedia spider venom elicited by mimotope peptides. Vaccine. 2011;29(45):79928001 .
34. Tambourgi DV, Paixão-Cavalcante D, Andrade RM, Gonçalves de Andrade RM, Fernandes-Pedrosa M de F, Magnoli FC, et al. Loxosceles sphingomyelinase induces complement-dependent dermonecrosis, neutrophil infiltration, and endogenous gelatinase expression. J Invest Dermatol. 2005;124(4):725-31.

35. Trindade AE. Hemograma do coelho normal e mixomatoso. Mem Inst Osvaldo Cruz.1954;52(2):397403.

36. Kozma M, Conner M. Anatomy, physiology and biochemistry of the rabbit in the biology of the laboratory rabbit. In: The Biology of the Laboratory Rabbit, New York, Academic Press. New York. 1974, pp. 50-72.

37. Song BZ, Donoff RB, Tsuji T, Todd R, Gallangher GT, Wong Dt. Identification in cutaneous of rabbit eosinophils healing wounds and heterophils. Histochem J. 1993;25(10):762-71.

38. Veiga SS, Zanetti VC, Franco CR, Trindade ES, Porcionatto MA, Mangili OC, et al. In vivo and in vitro cytotoxicity of brown spider venom for blood vessel endothelial cells. Thromb Res. 2001;102(3):229-37.

39. Bombeli T, Karsan A, Tait JF, Harlan JM. Apoptotic vascular endothelial cells become procoagulant. Blood.1997;89(7):2429-42.

40. Mackman N, Tilley RE, Key NS. Role of the extrinsic pathway of blood coagulation in hemostasis and thrombosis. Arterioscler Thromb Vasc Biol. 2007;27(8):1687-93. 